\title{
The Use of Persuasive Techniques in the Contents of Ghanaian Advertisement: An Exploratory Case Study of Tasty Tom Ntoso and Alomo Bitters Twa Bi Gye Wo De3 Promo Adverts on United Television (UTV)
}

\author{
Maame Efua Yamoawah Essel \\ Department of Communication Studies, University of Cape Coast, Ghana, West Africa
}

\begin{abstract}
The study was undertaken to find out the use of persuasive techniques in the contents of Ghanaian advertisement using tasty tom ntoso and alomo bitters twa bi gye wo de3 promo adverts on United Television (UTV) as a case study. Specifically, the study sought to identify the persuasive techniques used in the content of Tasty Tom Ntoso Promo advert and Alomo Bitters twa bi na gye wo de3 promo adverts on Televisions and its related impact on buyer and to find out what makes these persuasive techniques manipulative and its impact on buyers. It was revealed from the study that ethical appeal (ethos) was the most used persuasive strategy in the advertisement. That is to say, marketers put in much efforts in appealing to the ethical principles of buyers. The study equally discovered that setting the right tone and mood for an ad campaign message is key. Lastly, the researcher found out that, advert messages are framed to suit the particular targeted audience. If the advert is trying to appeal to young adults and teens, the message will more likely be informal and highly friendly. Based on the findings of the study, the following recommendations were made; producers of alcoholic drinks should tell the health implications of excess consumption of alcohol through their advert on television and there is the need for producers of food products to tell the right amount of the food ingredients for the preparation of food. This will help to address the problem of excessive use of food ingredients in food preparation
\end{abstract}

DOI: $10.7176 / \mathrm{NMMC} / 98-02$

Publication date:September $30^{\text {th }} 2021$

\subsection{Background of the study}

The history of advertising can be traced to ancient civilisations. It started back in Egypt where they used papyrus in promoting slaves' sales and rewards. Wall or rick paintings for commercial advertisements and political campaigns were usually common in Ancient Greece and Ancient Rome (Bhatia, 2000). "Ancient China can also be said to have produced the grassroots for advertising. It saw the earliest advertising called Oral, as recorded in the classic of Poetry ( $11^{\text {th }}$ to $7^{\text {th }}$ centuries BCE) of bamboo flutes played to sell candy." Advertisement usually took the form of calligraphic signboards, inked papers, and copper printing plates which were used to print posters in the form of a square sheet of paper with a rabbit log which had 'Jinan Liu's fine Needle Shop' and "We buy high quality steel rods and make fine quality needles, to be ready for use at home in no time' written above and below it. Hence, this was considered the world's earliest identified printed advertising medium (Liu, 2013). In the $19^{\text {th }}$ centuries, advertising was primarily based on newspapers and magazines until in the $20^{\text {th }}$ century when it grew rapidly with the emergence of new media such as direct mails, radio, internet, television, mobile devices among others.

Up until the early twentieth century, advertising took a different dimension all together. Owing to rapid urbanization, there was the need for mass production of goods. Rather than selling out in bits to local consumers, manufacturers sought for markets long way from their factories, and sometimes possibly from the other side of the world. This created a need for advertising where the manufacturers needed to explain and recommend their products to customers whom they would never meet personally. Manufacturers, in chasing far-off markets, were beginning to compete with each other. Therefore, they needed to brand their products, in order to distinguish them from one another, and to create mass recommendations to support the mass production and consumption models (Restrepo, 1996). Newspapers provided the ideal vehicle for this new phenomenon, advertisements. Eventually new technologies were also making newspapers cheaper, more widely available and more frequently printed. They had more pages, so they could carry more, and bigger adverts. Adverts came in simple descriptions of products, plus prices and the purpose these products served to potential consumers. Now, with the emergence of more convenient media and technological advancement, meant that illustration could be added to advertising, and colour was also an option. Advertisers started to add copy under the simple headings, describing their product using persuasive prose and this has been the norm ever since.

To some extent, we are surrounded by the media and what they present to us cannot be underestimated. It has reached a point where our very lives are so dependent on what we see on media. The television, radio, and the print medium (newspapers, magazines), have become a constant part of us. Even when one does not choose any of these traditional forms of media, ones' owing of a smartphone, makes him or her susceptible to these 
buzzes of information all over. Even though most people these days prefer getting glued to their smart devices, quite a number of television addicts are equally highly exposed to tons of messages, advertisement and other information that flashes on our television screens. The information we are served daily goes a long way to make an impact on our lives. One cannot deny that the weather forecast does affect our plans, neither can one deny too that, news stories do shape our opinions about people, places and surroundings. Similarly, we cannot also deny how the media mirrors our society through the reality shows, talk shows, soap operas and advertisements.

Advertisers deliberately put creative content together to make their products more preferable to other similar products on the markets. This is where they employ persuasive techniques to lure and establish their products in the minds of their potential consumers. The videography, pictures, choice of colours and even the choice of television stations to show these adverts are all planned and executed timely to attract their buyers. One would undoubtedly argue about why producers would spend so much money or resources on producing catchy adverts for a supposedly good product. It is a fact that advertisement or commercials are one of the major sources of finance to both the television stations running the adverts and to the producers themselves. This is because at the end of the day, when consumers are convinced enough, they will eventually purchase the products. If they are satisfied with the product, that is a plus to the producers, otherwise, it will be loss to the producers as consumers will shift their attention to other brand of the same products. Hence, undeniably, advertisements have some level of effects on us. The adverts may not directly mean anything to us but just as we keep consuming them unaware on our television screens, we are affected in a very subtle way by these adverts. If you watch or listen to one particular advertisement repeatedly, there could be some psychological pressure that convinces you into patronizing the product.

It is relevant to note that these advertisements specifically, have a goal, which is to actually persuade audiences to patronize the products and services being advertised. Therefore, although other forms of content displayed in the media may just shape us unconsciously, they do contain elements that make it a sure way of persuading audiences to react to their messages. The great impact of persuasion has propelled some scholars such as Richard M. Perloff, Robert Cialdini, L.J Shrum to conduct studies on persuasion over the years, to the extent of even propounding 'the persuasion theory', and leading to other scholars propounding other theories and ideologies. This is because of the importance and the inevitability of persuasion in our everyday communication. Humans adopt some form of persuasion in our daily lives, usually with the idea of getting a benefit from other people. It may be trying to convince friends to attend an event with us, trying to get money from parents or even from our employers at work to seek permission to be absent.

Persuasion, according to communication scholars, is a communication process in which the communicator seeks to elicit a desired response from his receiver (Andersen, 1971). To others, it is a successful intentional effort at influencing another's mental state through communication in a circumstance in which the persuadee has some measure of freedom (O'Keefe, 1990). Considering the concept more holistically, Perloff (2003) defined persuasion as a symbolic process in which communicators try to convince other people to change their attitudes or behaviour regarding an issue through the transmission of a message in an atmosphere of free choice. The end goal in persuasion within a communication setting is to cause a change in attitude or a change in the reaction of people towards something.

\subsection{Statement of Problem}

Nobody pays for an advert to tell you about alternatives. The main pressing reason that will call for running an advert for a product is to definitely persuade potential buyers (publics) into choosing that particular product over the other. These buyers live in a society bound by norms, values and cultural beliefs. The symbols, dances, colors, and language with its rich cultural meanings adopted in advertising are gripping and unconsciously influential. Though several scholarly studies have been conducted over the years concerning how advertisements impact on society, little has been said of whether consistent advertisings help to shape or mirror our immediate society regardless of the main objectives of advertising. For this reason, the researcher selected two different food products adverts (Tasty Tom Ntoso Promo) and (Alomo bitters twa bi na gye wo de 3 promo) on television to outline how the use of these persuasive techniques helps mirrors societal norms and values or reflects it to the audience.

\subsection{Objectives}

There are a number of ways advertisers strategically place their products on the minds of buyers. Advertisement is one surest way to craft a creative message, with the use of simple text and appropriate media to promote a brand or product. Hence for a better understanding, the study seeks:

1. to identify the persuasive techniques used in the content of Tasty Tom Ntoso Promo advert and Alomo Bitters twa bi na gye wo de3 promo adverts on Televisions and its related impact on buyer.

2. to find out what makes these persuasive techniques manipulative and its impact on buyers. 


\subsection{Research Questions}

To guide the researcher in conducting the research, the study will answer the following questions:

1. What persuasive rhetorics or techniques do Tasty Tom, and Alomo bitters employ in television advertisements?

2. What makes these persuasive techniques manipulative to some extent and in the end have an impact on buyers?

\subsection{Research Design}

A research design is the logic that links the data to be collected and the conclusions to be drawn to the initial questions of a study and ensures coherence (Rowley, 2002). It serves as an action plan for a study and gives a clear view of what is to be achieved at the end of the study. This study is a qualitative research which will employ the media content analysis in conducting the research. This is because, it seeks to find out not just the what but also the why and how advertisers use persuasive techniques to subtly influence buyers and to promote their products brands in Tasty Tom Ntoso Promo and Alomo Bitters twa na gye wo de3 promo adverts in Ghana, its impacts and to unravel how these adverts inadvertently shape or mirror societal values, norms and cultures.

\subsection{Research Site}

The research site chosen for this study is United Television (UTV), a newbie among television stations in Ghana; came into existence in 2013. The idea of the research was to find out how the use of persuasive techniques in advert is influential in consumer's decision making and the purposes for which these adverts are made. Frequently, it was realized by the researcher how the Tasty Tom Ntoso Promo and Alomo Bitters twa bi gye wo de3 promo advert run on UTV out of the numerous adverts. Hence, UTV was the most appropriate channel of advertisement to be used as the site for this study. Additionally, the researcher realized UTV has become one of the most-viewed television channels now in Ghana simply because of their adaptation to the use of the local dialects in almost all their programs, hence has a greater targeted audience. This makes it profitable for most food and beverage producers to use UTV as the preferred medium to reach potential buyers of their products and these selected adverts are of no exception.

\subsection{Sample Size and Technique}

The Tasty Tom Ntoso Promo and Alomo bitters twa bi gye wo de3 promo adverts were the two adverts sampled through purposive sampling among the many commercials on UTV. The sampling was limited to two adverts due to the similarities in the use of persuasive techniques in both adverts. The researcher specially focused on the two adverts, because they were popular promotion commercials running on UTV within the first half of 2020.

\subsection{Use of Content Analysis}

The daily human communication and the expressing of thoughts is made possible through the use of words. The words organized convey a message from person to person; hence, the interpretation of a message's content is called the content analysis. A brief history of the existence of content analysis shows how content analysis was a time-consuming process. Analysis was done manually, or using slow mainframe computers to analyze punch cards containing data punched in by human coders. Single studies could employ thousands of these cards and recorded lots of human errors. It was also time consuming; hence made this method impractical for large texts. However, despite its early complexities in the late 1940 s, by mid 1950 s, researchers were already starting to consider the need for more sophisticated methods of analysis, focusing on concepts rather than simply words, and on semantic relationships rather than just presence (de Sola Pool,1959). While both traditions still continue today, content analysis now is also utilized to explore mental models, and their linguistic, affective, cognitive, social, cultural and historical significance.

Many scholars have defined content analyzing in several ways. This is because of the quantitative and qualitative nature of content analysis. Neuendorf (2002) describes it as, the primary message centered methodology. He gives a strict interpretation of content analysis as being quantitative only; where quantitative only looks at media content analysis such as topics or issues, volumes of mentions, messages determined by key words in context, circulation of media (audience reach) and frequency. However, two other scholars by names, Shoemaker and Resse, propounded two other approaches to content analysis. They vehemently oppose Neuendorf's interpretation. Shoemaker and Resse (1996) categorize content analysis into behaviorist tradition and humanist tradition. The behaviorist approach to content analysis primarily deals with the effects that content produces and usually pursued by social scientists. The Humanist approach on the other hand, looks at how media content is used to try to identify what it says about society and culture. This dual view of the media content analysis births the aged debate over whether mass media create public opinion, attitudes, perceptions(effects) or whether it reflects existing values, societal norms and cultures. On either side, most researchers agree that with limitations, mass media do both. Weber (1990) and Neuman (1997) also says, content analysis is a research 
method that uses a set of procedures to make valid inferences from a text. Precisely, a technique for gathering and analyzing the content of text. The "content", in this aspect refers to the words, meanings, pictures, symbols, ideas, themes or any message that can communicated. This definition by Weber and Neuman respectively, forms the basis of this study because it focuses on the qualitative aspect of content analysis. This serves as the major and sole research methodology for this study.

Aside basing the analysis on the research questions in the subsequent chapter, the researcher will take some concepts in the adverts into consideration. These are:

- Texts analysis

- Narratology of the adverts, thus, will focus on the narrative or story telling within the advert with emphasis on meaning that may be produced by its structure and choice of words.

- Semiotics analysis (deals with signs in text and how viewers might interpret those signs).

- Adjectives used in descriptions (positive and negative) which gives strong indications of a speaker's and writer attitude.

- Use of metaphors and similes.

- Use of Active and Passive voice

- Narrator's point of view ( $1^{\text {st }}$ Person, $2^{\text {nd }}$ person or $3^{\text {rd }}$ person $)$

- Tonal qualities used in the adverts

- Visual imagery in text.

- Context factors (position and credibility of narrator)

The use of content analysis is to enable the researcher to have a close or critical look at the various texts in the form of persuasive rhetorics as used in the two selected adverts. Since it allows for both quantitative and qualitative operations, it helps looks at deducing or retrieving valuable and meaningful evidence or information from a piece of communication content (texts, audio, visuals or even hypertexts. Krippendorff (2018). The use of the qualitative content analysis became very prudent for the study owing to the unobtrusive nature of the phenomena, such that, the contents being analyzed are not influenced by researcher's presence, hence, free of any personal opinionated sides. Summarily, the methodology became needful to analyze the various factors of a phenomenon through the use of observations, texts and depth expressed in predominantly non-numerical form.

\subsection{Data Analysis}

\subsection{Summary of the advertisements}

\section{1.1 Alomo Bitters Twa Bi Gye Wo De3}

It is a minute and forty-two second advert. The ad opens with people chatting and entering a chop bar. A man's food is served but request for Alomo Kasapack as starters. He opens the pack after taking the content and realises he has won a goat. It continues by showing a picture of the goat on the pack, supposedly as evidence. Out of excitement, he leaves without touching his served meal and two other gentlemen who were waiting for their turn, take over his food. Another setting of the advert shows, a group of supporters in a drinking bar watching football. After taking a pack of the bitters, one of them opens it up and finds a prize of Flat screen. The others join him happily in his jubilation. It goes ahead to another scene where a lady is seen screaming out her prize of winning an Alomo customized shirt, with others winning a smartphone and a reward of a NASCO 40 inches LED TV. Moving on, another woman announces her prize of a hundred cedis shopping voucher.

To make the advert more natural and easily to be identified with consumers, it shows a setting where a man enters a drinking spot with looks of confusion written all over his face; wondering what was going on. He asked the bar attendant who briefs him on the purpose of people's excitement after taking the bitters. Translated in English, he explains, "Don't dispose of the kasapack after consumption. Open the pack, you stand a chance of winning any prize you see".

To the amazement of the man who looked confused, another person screams of winning a car which he plans of using for his taxi business. Another phase of the advert, shows the various prizes that are likely to be won by buyers during their 20 years anniversary of existence and operation. The advert then takes viewers aback to the first man who won the goat in the opening stages of the advert. He returns home with a live goat and a bunch of plantain with people sharing in his excitement. The advert eventually ends with a showcase of the new package of Alomo, a crest depicting their 20years celebration, terms and conditions apply, a show of their social media handles and a caution to the public to drink responsibly and not to be sold to people under 18 years, pregnant and lactating women. The standard approval by the FDA message also highlighted.

\subsubsection{Tasty Tom Ntoso Promo Advert}

It is a 34 seconds advert that begins with a narrator giving the details of the advert. This advert is made in the English language and it begins by the narrator saying, "Now everybody gets more in the Tasty Tom Ntoso promo. With $10 \%$ extra Tasty Tom tomato mix in every small sachet you buy. For every $70 \mathrm{~g}$ sachet of Tasty Tom rich in Tomatoes mix you buy you get $100 \%$ extra Tasty tomatoes mix for free. That means, extra nutrition 
and extra goodness. So, hurry, buy the $70 \mathrm{gh}$ sachet of Tasty Tom enriched Tomatoes mix to get your $10 \%$ extra ntoso. This offer is valid whiles stock lasts. The advert ends shortly with the usual standard approval from the FDA and a slogan which goes, Tasty Tom Tomatoes Mix, For tasty meals, good for you."

\subsection{Research Question One: What persuasive techniques do Tasty Tom and Alomo Bitters employ in television advertisements?}

This section will discuss the various persuasive techniques used in each of the adverts as seen in the selected television adverts summarized respectively in the aforementioned paragraphs.

\subsection{Persuasive techniques in the Alomo Bitters Twa Bi Gye wo De3. \\ 4.1.1 Tonal Qualities}

Neil Kokemuller (2007) defines Tone of voice in advertising as the intentional use of images, lighting, sound and written copy to create a specific tone or setting for an advertisement. This expression is most often used to describe the impact of creative copy in broadcast media and print ads. For the purpose of this study, it will be limited to broadcast media, thus, television. In the same way that a person's body language and vocal tone impact a message, an advertiser's use of various background elements and words can affect the interpretation of an advertisement. The tone of an advert influences the narratology of the advert campaign. It makes a huge difference in the way an advert is received by the consumer. The use of a more friendly and objective tone evokes a sense of wellbeing and upliftment for the consumer. In considering the tonal qualities employed in the Alomo Bitters Twa Bi Gye wo de3, the researcher identifies four tonal qualities that set the tone for the advert and was all in bid to persuade viewers potential buyers into purchasing. Thus, the appropriate use of tenses, mood, targeted age group, products being advertised.

\subsubsection{Use of tenses}

The use of third party or passive tense like "we" or "they", fetches less response for an advert as compared to the use of active tenses. When an advert makes use of more of "you", they gain more viewership. In the Alomo advert, advertisers made use of more "you" by employing two narrators and several other respondents who explained the details of the promo advert and expressed their excitement after opening the pack to see their prizes. This is very evidential from the transcribed version as seen above.

\subsubsection{Mood}

The mood behind an advert equally contributes to persuading consumers. It is well known that happy people will be more inclined to purchasing a product. This is why in most successful ads, there is usually an upbeat atmosphere to them. Visual ads will always show people with happy faces beaming with smiles, especially when they used the product or service. The sense of happiness or joy seen in the ad appeals to many consumers to purchase in order to experience this great feeling too. From the ad, this is so evidential as the respondents could not simply hide their excitement from winning different items after consuming a pack. Right from the beginning at the chop bar when a respondent left behind an earthenware bowl of fufu after realizing he has won a live goat as his prize and similarly seen with the subsequent respondents.

\subsubsection{Targeted Age groups}

Mostly, the targeted age group of the company's advert sets the tone of the advert. If the advert is trying to appeal to young adults and teens, its tone will be more informal and highly friendly. This is quite different for an advert campaign targeted at the aged, business people and even a gender centred advert. The language used are quite formal, technical and seem to impress especially with a particular gender that the advert seeks to please. In the advert, it could clearly be seen from all the scenes of the advert that, they carefully selected young people presumably above eighteen (18) years who unrestrictedly can take in these alcoholic beverages. The language use was also informal and friendly with a very happy and giddy atmosphere.

\subsubsection{Products and Services Rendered}

The tonal quality of an avert campaign may equally depend on the product and services being advertised. The type of product and the benefits consumers are bound to obtain mostly influences the tone of the advert. A viewer should be affected one way or the other positively after viewership. The images of happy consumers should be created so as to make viewers feel the joyous aura about the product. Similarly, in the ad, the producers were mindful of the product in question hence employed the use of energetic, young people beaming with all smiles. This sought to portray to consumers that, the intake of Alomo bitters gives energy, vibrance and makes one happy. To add more value and to promote the brand, this selected product was introduced to the market as part of their twenty years anniversary celebration.

\subsection{Narratology of advert}

The narratology of an ad campaign focuses on the narrative or story telling within a text with emphasis on the meaning that may be produced by its structure and choice of words. From the ad, the language used was less formal, persuasive and more of prioritizing the interest of the consumers. The advert entails eight respondents 
aside the main speakers who give a comprehensive explanation of the ad. The main speakers speak from $2^{\text {nd }}$ person narrative point of view by the use of "you". Advertisers employed this style of narrative to emphasis the value placed on buyers. As buyers are their most priority hence, the allocated prizes seen in any kasapack after consumption, it serves the interest of consumers. The level of premium placed on consumers is a form of persuasive technique used by the advertisers to convince buyers into buying with the notion that, the company (Kasapreko Alomo Bitters) has their interest at heart.

\subsection{Semiotics}

Under semiotics, an ad campaign focuses on signs and signs system in text and how viewers interpret (decode) those signs to influence a buyer's purchasing decisions. In the ad, the crest or logo depicting the 20 years celebration since its existence and operation is seen. This is a marketing effort aimed at developing the image of the company in order to create and strengthen a brand identity and then use that image to help the business reap specific benefits. Pictures of prizes shown at the back of the kasapack to also suggest the authenticity and genuineness of the brand. The symbols of the standard approval of the Food and Drug Authority (FDA) and an image depicting how people should drink responsibly and not advisable for persons under eighteen (18) years. Additionally, there is a symbol showing that the bitters is not healthy for pregnant women. This usually comes with the most alcoholic beverages which are sold and being advertised in Ghana. In order to protect the health of younger persons and pregnant women because the content may not be safe for their consumption.

\subsection{Celebrity endorsements}

Advertisers of the Alomo realising the importance of celebrity endorsements as one of the key tactics in persuading buyers into purchasing a product, took advantage of this technique by using one celebrity in the ad. In the opening of ad, a popular celebrity by name "Oteele" was figured. He is mostly seen on our television screens in some programs such as, "payday", "cow and chicken" and "Devil under my pillow". Celebrity endorsement is one of the major marketing strategies for advertisers. They are often famous celebrities or experts who hold expertise, awareness and attractiveness and can transmit product messages to catch the attention of consumers in a short time and further influence a consumer's purchasing decision.

A Taiwanese study by Dr. Hsinkuang Chi from Nanhua University, Taiwan, shows that consumers show greater recall of products that have been endorsed by celebrities regardless of whether they are actual fans or not. The ad used a celebrity to promote the kasapack, build trust and familiarity. They used Oteele, who is a celebrity so consumers can feel more sympathetic towards the brand. This subconsciously will make them believe that purchasing a product that is promoted by a celebrity they admire will allow them to emulate the celebrity's desired traits or attract similar people into their lives.

\subsection{Persuasive techniques in Tasty Tom Ntoso Promotion advert \\ 5. 1. Use of language}

Language has a powerful influence over people and their behaviour. The choice of language to convey specific messages with the intention of influencing people is vitally important. Visual content and design in advertising have a great impact on the consumer, but it is language that helps people to identify a product and to remember it (Kanan and Tyagi, 2013). Because tomatoes are commonly used food commodities in many homes in Ghana, the ad sought to use a more comprehensive message in the ad to get the attention of the many to know and purchase the product. The use of "Ntoso" in the local dialect means "an addition of something" meaning, consumers get an additional pack when they make purchases of any quantity. It serves as a form of rhetoric to get a wider population of the targeted audience of the advert to patronize the product.

\subsection{Semiotics}

A critical look at the semiotics of the advert depicts several symbols, expressions and signs. Examples include a circular image giving the pictorial benefits of consuming Tasty Tom Mix. This is a creative and a simple way of summarizing the nutritional components of the product. That is, it shows how Tasty Tom contains enriched vitamins and fibre which aids digestion, strong bones, healthy eyes and helps boost one's immunity against diseases. Consumers would want the best for themselves hence seeing this can influence their decisions into purchasing. Additionally, the use of some expressions such as, "extra nutrition", "extra goodness in each pack for free", "enriched" ,10\% extra free". These expressions are repeated throughout the ad, place emphasis on the fact that, when a consumer purchases a $70 \mathrm{~g}$ sachet of Tasty Tom, obtains the aforementioned expressions above.

\subsection{Visual Imagery}

The use of colourful packages with a combination of red and yellow colours on a brightly coloured yellow background is to appeal to the eyes of buyers. Red symbolising the colour of tomatoes, while the yellow was meant to make the black writing pop out well for clarity, attract consumers and eventually persuade them to 
make purchases. Also, the yellow colour signifies brightness, positivity and reassurance that consumers will derive more (extra goodness) after each consumption.

\subsection{Research Question Two: What makes these persuasive techniques in the advert have an impact on buyers?}

There are a lot of persuasive techniques being used by many advertisers. Marketers are trying so hard to unearth all the hidden factors of human nature which might be helpful in attracting attention and hitting on psychological revelations in their marketing campaigns.

The identified techniques in both adverts adversely have impact on consumers. Consumer's thinking process, decision to purchase and final decision to patronize a product sometimes are as a result of influences from adverts. In the Alomo Bitters and Tasty Tom promotion adverts, it could be clearly seen that, the aforementioned techniques such as tonal qualities, use of tenses mood, targeted audience, narratology, semiotics, celebrity endorsements in the adverts were all for a purpose.

The persuasive techniques have impact on consumers as they provide them with the necessary information about a product to help them influence their purchasing decision. This is because, most of the information that makes consumers want to buy a product are normally obtained from advertisements. The nutritional composition, benefits and other vital information about a product are seen through advertisements hence marketers are very mindful of the message and the techniques they put in place to persuade buyers.

The colourful exposure of these adverts can also impact consumers' decision. The introduction of new Alomo Bitters Kasapack packages as part of celebration twenty years of existence as well as that of the Ntoso adverts, have the tendencies of influencing consumer's purchasing decisions. It shows the significant roles that the attractiveness of a package can increase sales, hence most marketers put premium and efforts in always providing a product with the best and colourful packages as ever.

The use of happy characters to portray one's excitement and satisfaction after taking a product, has an impact on consumers. The giddiness seen in the advert is what will be retained in the minds of the consumer. The stronger the sensory appeal in these tools, the greater the effect the tone has on the audience's interpretation.

Additionally, celebrity endorsements make a brand stand out. It involves the signing on of a celebrity for an advert and this comes everything that comes with that celebrity in question. The celebrity endorsement builds credibility and trust in the minds of consumers, polishes image of the brand. Studies have shown that using celebrities in advertising increases an advert campaign's persuasiveness which results in consumers having a better recall and recognition for a product (Zhou \& Whitla, 2013).

\subsection{Summary of the study}

Advertisement has become inevitable in these contemporary times. Each and every day, people come into contact with several advertisements. However, what makes an advertisement stay in the minds of its audience is the presence of some persuasive elements. Advertising is the subtle lure of getting a product to be known and purchased. Persuasive elements have emerged as an indispensable tool in media advertisement.

The key objectives of the study were to identify the persuasive techniques used in the content of Tasty Tom Ntoso promo advert and Alomo Bitters twa bi na gye wo de3 promo adverts on Televisions respectively. Additionally, the study aimed at finding out what makes these persuasive techniques manipulative and its impact on buyers. These two ads were chosen because they were both promotional advertisements that gained attention among Ghanaians and was run frequently on United Television (UTV) within the first half of 2020. The purposive sampling method was employed to select the two transcribed ads for the study.

The study tried to answer the following specific research questions which were finding out the persuasive rhetorics or techniques do Tasty Tom, and Alomo bitters employ in television advertisements and what makes these persuasive techniques manipulative to some extent and in the end have an impact on buyers.

In view of the aforementioned research questions, the researcher adopted the conceptual content analysis approach. The purpose of using qualitative content analysis was because, with the qualitative method, it made it possible for the researcher to analyse the various factors of a phenomenon through the use of observations, texts and depth expressed predominantly in a non-numerical form. The framework for the study revealed that ethos, logos and pathos are key elements behind persuasion.

\subsection{Major Findings in the study}

Following the analysis and discussion of the data, some key findings were discovered. It emerged that ethical appeal (ethos) was the most used persuasive strategy in the advertisement. That is to say, marketers put in much efforts in appealing to the ethical principles of buyers. This was evident in the Alomo Bitters Ad where a celebrity was used in delivering the message. Before a prospective audience will want to sit and pay attention to an advertisement, the credibility of the messenger is key. People will give audience to a person they see as credible and trustworthy and especially pertaining to an edible product. Advertising endorsers help polish the 
image of the brand and help increases an advert campaign's persuasiveness which results in consumers having a better recall and recognition for a product. The involvement of a celebrity gained the attention of the audience as he possesses a credible personality and well known in the local movie industry even aside his speech. Just as Aristotle (2007) puts it, "there is persuasion through character whenever the speech is spoken.

The study equally discovered that setting the right tone and mood for an ad campaign message is key. The tone of an advert influences the narratology of the advert campaign. It shows how an advert will be received by the consumer. The use of a more friendly and objective tone evokes a sense of wellbeing and upliftment for the consumer. However, the tone of the ad is dependent on the type of product being advertised. In both ads, a friendly, non-opinionated and a more objective tone was utilised. It makes the message of the advert more comprehensive. With respect to the mood for an ad campaign, it was also found out that, Positivity and smiles were the only emotions that were depicted in the advertisements. The use of fear and dominance by some advertisers to get their messages to their audience were absent in all two advertisements proving that, an appeal to the right emotions of audience especially for broadcast media plays a major role in persuading the buyers.

Lastly, the researcher found out that, advert messages are framed to suit the particular targeted audience. If the advert is trying to appeal to young adults and teens, the message will more likely be informal and highly friendly. However, it is quite different for an advert campaign targeted at the aged, business people or even a gender centred advert. The message used will be quite formal, technical and seem to impress especially with a particular gender that the advert seeks to please.

\subsection{Conclusions}

In recent times, the act of persuasion in advertising has become a very powerful tool in the world of advertising. Consumers purchasing decisions are mostly influenced by the contents of an ad were subtly or not. Before a consumer makes a decision of purchasing a product, a buying decision-making process is undertaken. This process is called a cognitive process. This is because, consumers are daily exposed to wide and thousands of ads that persuades them to patronize a one product or the other, hence the need for a cognitive activity to decide whether to buy or not. Hence though, marketers do well to inculcate persuasiveness in their ads, the greater responsibility lies on the consumer whether to succumb to such persuasive techniques or not.

\subsection{Recommendations}

From the key findings and the conclusions drawn from the study, the following recommendations are made.

1. Producers of alcoholic drinks should tell the health implications of excess consumption of alcohol through their advert on television.

2. There is the need for producers of food products to tell the right amount of the food ingredients for the preparation of food. This will help to address the problem of excessive use of food ingredients in food preparation.

\section{REFERENCES}

Ajzen, I. (1992). Persuasive communication theory in social psychology: A historical perspective. Influencing Human Behavior, 1-27.

Allport, G. W. (1935). Handbook of social psychology. Worchester, MA: Clark University Press.

Restrepo, B. (1996). Efren: Pre- history of advertising administration. North University. 2: 4549.

Bhatia, K. (2000). Advertising in rural India: Language, Marketing Communication, and Consumerism, 62, 6874.

Cialdini, R. B. (2001). Influence: Science and practice (4 ${ }^{\text {th }}$ ed.). Boston: Allyn \& Bacon.

Cialdini, R. B. (2009). Influence: Science and practice ( $5^{\text {th }}$ edition). Boston, MA: Pearson Education.

Coker, O., \& Oke, R. S. (2012). "Arts For Ad Sake": Advertising Language As Literary Language In Selected Advertising Copy In Nigeria. In The African symposium: an online journal of the African educational research network (Vol. 12).

Cole, F. L. (1988). Content analysis: Process and application. Clinical Nurse Specialist, 2(1), 53-57.

de Sola Pool, I. (1959). Trends in content analysis. Urbana, Ill: University of Illinois Press.

Doob, L. (1947). The behaviour of attitudes. Psychological Review, 54(3), 135-156.

Eckhardt, G., \& Bengtsson, A. (2008). Pulling the white rabbit out of the hat: consuming brands in imperial China. Advances in Consumer Research, 8, 96-127.

Eckhardt, G., \& Bengtsson, A. (2010). A brief history of branding in China. Journal of Macromarketing, 30(3), 45-56.

Eisenhardt, K. M. (1989). Building theories from case study research. Academy of Management Review, 14(4), $532-550$

Liu, H. (2013). Chinese business: Landscapes and strategies. Retrieved from https://www.amazon.com

Kokemuller, N. (2007). The importance of brand awareness. Journal of Marketing, 57(1), 1-22. 
Kotler, P., \& Keller, K. (2009). Marketing management (12 ${ }^{\text {th }}$ ed.). New Delhi: Prentice-Hall of India.

Krippendorff, K. (2018). Content analysis: An introduction to its methodology. London: Sage publications.

Lamichhane, Y. R. (2017). The role of Aristotelian appeals in influencing consumer behavior. Journal of Development and Social Engineering, 3(1), 65-78.

Macnamara, J. (2003). Mass media effects: A review of 50 years of media effects research. Asia Pacific Public Relations Journal, 6(1), 1-34.

Moore, B. C. (1993). Frequency analysis and pitch perception. Human Psychophysics, 56-115.

Neuendorf, K. (2002). The content analysis guidebook. Thousand Oaks, CA: Sage Publications.

Neuman, W. (1997). Social research methods: Qualitative and quantitative approaches. Needham Heights, MA: Allyn \& Bacon.

O'Keefe, R. (2002). Persuasion: Theory and research. Thousand Oaks, CA: Sage Publications.

Perloff, M. R. (2003). The dynamics of persuasion. Mass Communication and Society, 18(6), 701-729.

Perloff, R. M. (2010). The dynamics of persuasion: Communication and attitudes in the twenty-first century. London: Routledge.

Rizwan, M., Pirzada, S., Sohail, A., Nadeem, M., \& Murid, W. (2013). The role of advertising appeals, role of celebrity \& expert in tv advertising attitude. IOSR Journal of Business and Management, 52-57.

Rowley, J. (2002). Using case studies in research. Management Research News, 25(1), 16-27.

Samuel-Azran, T., Yarchi, M., \& Wolfsfeld, G. (2015). Aristotelian rhetoric and Facebook success in Israel's 2013 election campaign. Online Information Review, 39(2), 90-108.

Shoemaker, P. \& Reese, S. (1996). Mediating the message: Theories of influences on mass media content. White Plains, NY: Longman.

Sparks, J. R., \& Areni, C. S. (2008). Style versus substance: Multiple roles of language power in persuasion. Journal of Applied Social Psychology, 38(1), 37-60.

Weber, R. (1990). Basic content analysis (2 ${ }^{\text {nd }}$ ed.). Newbury Park, CA: Sage.

Zhou, L., \& Whitla, P. (2013). How negative celebrity publicity influences consumer attitudes: The mediating role of moral reputation. Journal of Business Research, 66(8), 1013-1020.

https://www.youtube.com/watch?v=X2wEeK18TIs

https://www.facebook.com/AlomoBase/videos/484562429044879/ 